\title{
ANALISIS TOKOH DAN PENOKOHAN DALAM NOVEL AMULET DARI NUBIA KARYA MARGA T (PENDEKATAN PSIKOLOGI SASTRA)
}

\author{
Stelia Sugianto \\ Universitas Pattimura \\ e-mail: steliasugianto93@gmail.com
}

\begin{abstract}
Abstrak: Penelitian ini berjudul "Analisis Tokoh dan Penokohan dalam Novel Amuletdari Nubia Karya Marga T". Penelitian ini bertujuan mendeskripsikan tokoh dan penokohan yang terdapat dalam novel Amulet dari Nubia Karya Marga T. Sumber data penelitian ini adalah novel Amulet dari Nubia Karya Marga T. Penelitian menggunakan pendekatan psikologi sastra. Teknik pengumpulan data dalam penelitian ini adalah teknik membaca, mencatat, menandai, mengumpulkan dan mengklasifikasi data. Hasil penelitian ini merujuk pada tokoh dan penokohan. Adapun tokoh meliputi : (1) tokoh utama, (2) tokoh protagonis, (3) tokoh antagonis, (4) tokoh sederhana dan (5) tokoh komplek. Adapun watak tokoh meliputi: (1) penurut, (2) peduli dan berkorban, (3) penyayang, (4) jujur, (5) kuatir, (6) rasa ingin tahu, (7) mengagumi orang lain, (8) cemas, (9) heran, (10) tidak mudah putus asa, (11) pemalu, (12) jahat, (13) pendendam, (14) suka bergaul bebas, (15) licik, (16) serakah, (17) sombong, (18) baik hati, (19) perhatian, (20) gelisah, (21) perhatian, (22) kuatir, (23) prihatin, (24) penakut, dan (25) penipu.
\end{abstract}

Kata Kunci: Analisis, Tokoh, Penokohan, Psikologi Sastra 


\title{
CHARACTERIZATION AND ANALYSIS IN NOVEL AMULET FROM NUBIA KARYA MARGA T (LITERATURE PSYCHOLOGICAL APPROACH)
}

\author{
Stelia Sugianto \\ Universitas Pattimura \\ e-mail: steliasugianto93@gmail.com
}

\begin{abstract}
This study is entitled "Figure Analysis and Characterization in the Amulet Novels from Nubia Karya Marga T". This study aims to describe the characters and characterizations contained in the novel Amulet from Nubia Karya Marga T. The source of this research data is the Amulet novel from Nubia Karya Marga T. The research uses a literary psychology approach. Data collection techniques in this study are techniques of reading, recording, marking, collecting and classifying data. The results of this study refer to figures and characterizations. The characters include: (1) the main character, (2) the protagonist, (3) the antagonist, (4) the simple character and (5) the complex character. The characters include: (1) submissive, (2) caring and sacrificing, (3) merciful, (4) honest, (5) worrying, (6) curiosity, (7) admiring others, (8) worrying , (9) surprised, (10) not easily discouraged, (11) timid, (12) evil, (13) vindictive, (14) sociable, (15) cunning, (16) greedy, (17) arrogant , (18) kindhearted, (19) considerate, (20) restless, (21) considerate, (22) worried, (23) concerned, (24) timid, and (25) deceitful.
\end{abstract}

Keywords: Analysis, Figure, Characterization, Psychology of Literature 


\section{A. PENDAHULUAN}

Manusia adalah makhluk yang bebas dan pemilih, yang bisa mencari jalan nasibnya sendiri. Di sisi lain, manusia ditentukan oleh garis keturunannya. Manusia memiliki sifat lahiriah dan mulai berkembang sehingga memiliki dua sisi yaitu sisi kebaikan dan keburukan. Manusia adalah mahkluk yang memiliki cita rasa yang tinggi. Dengan adanya cita rasa yang tinggi tersebut, maka akan terbentuklah suatu karakter pada manusia. Karakter adalah suatu ciri khas yang dimiliki manusia untuk membedakan antara manusia yang satu dengan manusia yang lain. Dengan adanya karakter pada manusia, maka akan timbul suatu permasalahan atau ketidakcocokan. Agar kehidupan dapat berjalan dengan tenang dan lancar, maka seseorang harus memikirkan cara keluar dari suatu konflik. Manusia harus mengontrol ego dan menerima saran atau kritik dari orang lain.

Berkaitan dengan permasalahan hidup yang dihadapi oleh manusia, karya sastra adalah salah satu pemikiran atau pandangan seseorang yang diungkapkan sesuai dengan pengalaman yang dilihat, dirasakan bahkan didengar olehnya. Permasalahan yang dialami manusia dan cara penyelesaiannya menarik untuk dituangkan dalam bentuk karya sastra. Liku-liku kehidupan yang dialami manusia memberikan nuansa etnik pada suatu karya sastra. Para sastrawan menuangkan ide berupa karakter-karakter yang berbeda-beda dan mencoba menyampaikan pesan kepada pembaca tentang cara penyelesaiannya. Maka dari itu, para sastrawan memiliki peran yang sangat penting dalam perkembangan sastra. Dengan ide-idenya, pembaca mendapatkan suatu pesan baik itu tersirat maupun tersurat dari karya sastra tersebut. Sastra adalah lembaga sosial yang menggunakan bahasa sebagai medium: bahasa itu sendiri merupakan ciptaan sosial. Sastra menampilkan gambaran kehidupan; dan kehidupan itu sendiri adalah suatu kenyataan sosial Damono dalam (Priyatni, 2012:12). Dalam pengertian ini, kehidupan mencakup hubungan antarmasyarakat, antara masyarakat dengan orang-seorang, antar-manusia, dan antarperistiwa yang terjadi dalam batin seseorang.

Karya sastra dari kemunculannya hingga sampai saat ini mempunyai banyak keragaman jenis dan telah digolongkan dalam beberapa genre. Salah satu genre karya sastra tersebut adalah prosa. Prosa sendiri identik dengan sebuah karya sastra yang termasuk fiksi, rekaan, penuh dramatisasi, dan pengembangan ide kreatif dari sang pengarang. Prosa tidak hanya berbicara tentang karya fiksi, karena ada juga prosa yang disebut sebagai karya nonfiksi yang merupakan pertentangan dari karya fiksi. Meskipun begitu, peneliti hanya akan membahas pada karya fiksi saja. Di antara banyaknya karya-karya fiksi, novel termasuk ke dalam salah satu genre prosa yang bersifat fiksi. Novel adalah suatu cerita prosa fiksi dalam panjang yang tertentu, yang melukiskan parah tokoh, gerak serta adegan kehidupan nyata yang representatif dalam suatu alur atau suatu keadaan yang agak kacau dan kusut (Tarigan, 1984:164). 


\section{B. METODE PENELITIAN}

Penelitian ini bersifat kualitatif yaitu penelitian yang menggunakan latar alamiah dengan maksud menafsirkan fenomena yang terjadi dengan melibatkan berbagai metode yang ada Denzin dan Lincoln dalam Moleong (2012:5). Jadi, dalam penelitian ini peneliti mendeskripsikan secara alamiah data dari proses interaksi dengan objek yang diteliti yaitu novel Amulet dari Nubia karya Marga T. Penelitian ini bersifat deskriptif, yaitu memberikan gambaran secara jelas tentang bagaimana analisis penokohan tokoh dalam novel Amulet dari Nubia Penelitian yang dilakukan berdasarkan ciri- ciri penelitian kualitatif menurut Moleong (2012:8-12), yaitu:

(1) Data bersifat alamiah natural setting. Dalam hal ini data alamiah tetap terkait sepenuhnya dengan konteks, dengan sendirinya unsur-unsur yang terkait dengan konteks misalnya tindakan, ucapan, dan gerak isyarat tidak diabaikan dengan penelitian ini, supaya peneliti tidak kehilangan segala kepentingan yang berhubungan dengan konteks tersebut;

(2) Manusia sebagai instrumen penelitian. Dalam konteks ini manusia bermanfaat untuk menangkap makna dan nilai-nilai lokal yang berbeda. Manusia dikatakan sebagai instrumen penelitian sebab ia merupakan perencana, pelaksana, pengumpulan data, dan pada akhirnya ia menjadi pelapor hasil penelitian;

\section{Data dan Sumber Data}

\section{a. Data}

Data dalam penelitian ini adalah kata-kata, kalimat atau teks yang mengacu pada representasi tokoh utama dalan novel Amulet dari Nubia karya Marga $\mathrm{T}$.

\section{b. Sumber \\ Data}

Sumber data penelitian ini adalah novel Amulet dari Nubia karya Marga T yang diterbitkan oleh PT Gramedia Pustaka Utama, Jakarta 1999 dengan tebal 688 halaman.

\section{Teknik Pengumpulan Data}

Beberapa langkah yang ditempuh untuk mengumpulkan data penelitian adalah sebagai berikut:

a) membaca literatur kepustakaan yang relevan dengan judul penelitian dan masalah yang akan diteliti;

b) membaca keseluruhan isi novel Amulet dari Nubia karya Marga $\mathrm{T}$ secara berulang-ulang serta teliti;

c) peneliti menandai dan mencatat kalimat dan paragraf yang berhubungan dengan tokoh dan penokohan novel Amulet dari Nubia karya Marga T. 
d) peneliti mengumpulkan data mengenai tokoh dan penokohan novel Amulet dari Nubia karya Marga T; dan

e) setelah data terkumpul peneliti mengklasifikasi data sesuai dengan tokoh dan penokohan novel Amulet dari Nubia karya Marga T.

\section{PEMBAHASAN}

1. Tokoh

a. Tokoh Utama

1. Fertiti

b. Tokoh Protagonis

1. Fertiti

2. dr. Kamal

3. Pak Lobin

4. Mbok Susi

5. Aisha

6. Tira

c. Tokoh Antagonis

1. Merti Osorkon

2. Vasthi

3. Dokter Saul

4. Nalub

d. Tokoh Sederhana

1. Tante Oda

2. dr. Kamal

3. Nita

4. Pak Lobin

e. Tokoh Komplek

1. Merti Osorkon

2. Tante Oda

3. dr. Kamal

4. Nita

5. Pak Lobin

6. Mbok Susi

\section{Perwatakan}

a. Tokoh Utama

Tokoh utama yang terdapat dalam novel Amulet dari Nubia karya Marga T, yaitu Fertiti (Nefertiti) atau akrab dipanggil Titi, karena tokoh ini menjadi sorotan utama dalam penceritaan keseluruhan novel. Penelusuran ini didasarkan pada intensitas kemunculan tokoh dalam peristiwa yang membangun cerita dari peristiwa awal sampai akhir cerita.

b. Tokoh Protagonis 


\section{Fertiti}

a) Penurut

Penurut adalah sikap patuh terhadap seseorang, melakukan apa yang diminta orang lain dan tidak melawannya. Watak penurut pada tokoh Fertiti terlihat dari caranya menanggapi permintaan atau masukan dari orang disekitarnya. Fertiti selalu melakukan apa yang diminta atasannya. Dia tidak berfikir terlebih dahulu atas permintaan atasannya dan tidak melakukan perlawanan. Hal tersebut sesuai dengan kutipan berikut.

Sebenarnya Dokter Fertiti sudah mau pulang sejak siang, tapi atasannya, Dokter Saul tidak mengizinkan. Memang banyak pasien gawat, yang baru maupun yang post-op. Selama bertugas tentu saja dia tidak dapat meluapkan perasaannya, terpaksa tetap tersenyum dan menanggapi semua pertanyaan dari pasien-pasien yang ketakutan menghadapi penyakit mereka. "Ti, aku harus bicara denganmu." "Aku sedang sibuk, Ki. Apa enggak bisa ditunda?" tanyanya, menoleh sejenak. Dilihatnya Kiki menggeleng dengan wajah mendung. "Penting sekali?" "Sangat!" Fertiti menghela napas. "Oke. Beri aku lima menit saja. Aku akan segera beres dengan Pak Husein ( $\mathrm{T}$ Marga, 2004:7-8). Sikap penurut Fertiti terlihat ketika ia sudah mau pulang, namun atasannya tidak mengizinkannya untuk pulang, dikarenakan banyak pasien yang gawat darurat. Sikap Fertiti yang penurut itu, ia tidak bisa marah atasannya namun menerimanya dengan senyuman. Tidak hanya itu saja, sikap penurut pada tokoh Fertiti juga terlihat ketika dia menuruti permintaan sang ibu yang menyuruhnya tidak boleh pergi dari rumah. Hal tersebut sesuai dengan kutipan berikut. "Ibuku sebenarnya kurang setuju aku masuk FK. Maunya, aku terjun ke dunia usaha meneruskan jabatannya kelak. Tapi aku ngotot, jadi direlakannya dengan syarat, aku enggak boleh pergi jauh dari rumah (T Marga, 2004:46).

Kutipan di atas menjelaskan bahwa sang ibu yang ingin anaknya untuk mengikuti jejaknya untuk terjun ke dalam dunia usaha, namun keinginannya tidak diterima oleh Fertiti. Ibunya terpaksa mengikuti kemauan anaknya dengan satu syarat bahwa Fertiti tidak boleh pergi jauh dari rumahnya.

\section{b) Penyayang}

Sifat penyayang didalam diri seseorang tumbuh dengan sendirinya dan sudah ada sejak orang itu kecil. Maka dari itu sifat penyayang dalam diri seseorang hendaklah dapat diwujudkan atau diterapkan dalam kehidupan seharihari di dalam kehidupan bermasyarakat, terutama apabila kita melihat disekeliling kita yang sedang mengalami kesusahan, maka kita hendaklah membantu semampu kita baik berupa tenaga, materi dan pikiran kita karena dengan demikian kita telah dapat menerapkan rasa kasih sayang kita terhadap sesama yang memerlukan bantuan kita. Hal ini juga dapa terlihat pada sosok tokoh Fertiti dalam novel Amulet dari Nubia. Fertiti adalah tokoh utama yang sangat menyayangi keluarganya dan orang disekitarnya. Dapat dilihat pada 
kutipan berikut. Dengan mata berlinang, Fertiti melepaskan tangannya dari genggaman, lalu dirangkumnya kedua pipi Tante Oda, diciumnya, dibasahinya dengan air matanya, lalu dibisikkannya ke telinganya, "Mami!" Dan air matanya pun mengucur deras, membasahi selimut di bagian dada pasien ( $\mathrm{T}$ Marga, 2004:315).

Kutipan di atas menjelaskan bahwa Tante Oda ingin sekali agar Fertiti memanggilnya mami, setelah kematian ibunya Merti Osorkon. Mendengar permintaan Tante Oda membuat Fertiti merasa aneh, namun hati kecilnya terketuk melihat Tante Oda yang terbaring lemah di tempat tidur. Fertiti mengingat semua kasih sayang dan kebaikan yang diterimanya dari Tante Oda. Fertiti pun menerima permintaannya Tante Oda. Dengan air mata berlinang, Fertiti merangkum kedua pipi Tante Oda dan menciumnya dan berbisik ditelinga Tante Oda, "Mami”. Fertiti sangat menyayangi Tante Oda karena ia telah memperlakukan Fertiti sejak kecil seperti anaknya sendiri.

2. dr Kamal

a) Baik Hati

Sikap baik Kamal terlihat jelas pada saat Katrin dan Vasthi ingin menjebak Fertiti. Hal tersebut dapat dilihat pada kutipan di bawah ini. Kamal segera bangkit, nyaris melempar gelasnya ke atas meja, lalu berlari turun. “Tunjukkan di mana dia!" serunya (T Marga, 2004:51). Sifat baik Kamal terlihat pada saat Katrin dan Vasthi menjebak Fertiti untuk meminum alkohol yang banyak sampai Fertiti tidak sadarkan diri dan akhirnya pingsan. Kamal yang mendengar tentang Fertiti pingsan segera bangkit dari tempat duduknya dan berlari mencari dimana Fertiti berada. Setelah ia mendapatkan Fertiti yang terbaring di ranjang dengan dada cuma bertutupkan $\mathrm{BH}$ yang terbuat dari renda. Kamal dengan cepatnya meraba nadi, diperiksanya semua badan dan kepala Fertiti, karena ia takut terjadi sesuatu padanya. Setelah memastikan bahwa Fertiti tidak dalam bahaya, Kamal pun mengambil pakaian Fertiti dan ditutupi kepada Fertiti.

c. Tokoh Antagonis

1. Merti

Osorkon

a) Jahat

Rencana jahat merupakan perasaan hati yang berupa sebuah keinginan. Rencana juga dapat disebut dengan angan-angan, kemauan, niat ataupun harapan. Seperti yang terlihat dalam kutipan berikut. "Jangan ngomong sembarangan! Kau enggak boleh pacaran sama dia!" (T Marga, 2004:11). "Titi, aku bisa melenyapkan anak itu dalam sekejab mata kalau aku mau! Ngertiii! Jangan coba-coba sama aku ya! Kalau kau enggak percaya, teruskan hubunganmu, lihat nanti apa akibatnya!” (T Marga, 2004:12). 
Merti sangat melarang Fertiti untuk tidak berpacaran dengan lelaki siapa pun. Ibunya selalu menghalangi hubungannya dengan Hadi, lelaki yang sekarang dekat dengannya. Ibunya sangat marah ketika tahu bahwa Fertiti dan Hadi berpacaran, dengan alasan bahwa setiap lelaki yang mendekati anaknya hanya ingin mengincar harta anaknya saja. Sehingga ibunya mengancam untuk dapat melenyapkan Hadi dalam sekejab apabila Fertiti mau terus berhubungan dengan Hadi. Tidak hanya itu saja, sikap jahat Merti juga terlihat ketika Fertiti menanyakan keberadaan ayahnya. Hal tersebut sesuai dengan kutipan berikut. "Jadi anak jangan sok mau tahu urusan orang tua! Kemana kek ayahmu, kau enggak perlu Tanya!'(T Marga, 2004:19).

Sejak lahir, Fertiti tidak pernah mengenal siapa ayahnya. Tidak ada potretnya sehelai pun di dalam rumah. Ketika Fertiti duduk di kelas empat, ia pernah menanyakan pada ibunya di mana ayahnya. Tetapi reaksi yang diperolehnya adalah bentakan mengguruh yang terngiang di telinganya sampai ia tumbuh menjadi dewasa. Hal itu membuatnya tidak berani bertanya-tanya lagi walaupun keherannya masih belum terjawab.

\section{Dokter Saul}

a) Jahat

Sifat jahat dokter Saul terhadap Fertiti dapat dilihat pada kutipankutipan di bawah ini. Saul tidak perlu berpikir lama, dia segera mengambil keputusan, "Aku bisa menekannya supaya keluar dari sini. Tapi sebelum itu, akan kupaksa dia menyerah padaku. Jangan kuatir, Bu. Semua akan terjadi sesuai dengan keinginanmu. Setelah kuperoleh dirinya,akan kutendang dia dari sini. (T Marga, 2004:472-473). Saul mengambil keputusan untuk mengeluarkan Fertiti dari klinik tempat ia bekerja dengan alasan bahwa foto yang diberikan Vasthi kepadanya sangat mengganggu ketentraman masyarakat. Selain itu juga sebelum ia mengeluarkan Fertiti, ia merencanakan memaksa Fertiti untuk menyerah padanya. Dan ketika ia mendapatkan tubuh Fertiti seutuhnya,barulah ia menendangnya keluar.

\section{d.Tokoh Sederhana}

\section{Tante Oda}

\section{a) Penyayang}

Di dalam kasih terdapat kasih sayang yang dapat diartikan sebagai cinta, kasih amat suka akan sesuatu objek yang mempunyai perasaan kasih sayang. Dalam cinta kasih juga terdapat adanya cinta persaudaraan. Cinta persaudaraan biasanya diwujudkan dalam tingkah laku manusia yang memiliki tali persaudaraan. Cinta persaudaraan juga tidak mengenal adanya batas-batas manusia yang berdasarkan suku bangsa, bahasa maupun agama. Dalam cinta ini semua adalah sama. Hubungan persaudaraan biasanya terjadi dalam sebuah keluarga. Hal ini bisa dilihat pada kutipan di bawah ini. "Oh, anakku yang malang, maafkan ibumu. Dia melakukannya demi 
kebaikanmu..." Tante Oda mendadak terisak, membuat Fertiti jadi kaget setengah mati (T Marga, 2004:314).

Kutipan di atas menjelaskan bahwa Tante Oda mengelus Fertiti dengan kasih sayang, tertawa menghibur Fertiti yang sedih sambil menasihati bahwa anakku yang malang, jangan bersedih, ibumu pasti tidak bakal membuatmu sengasara. Mungkin Oom Frangky keliru menafsirkan pesannya. Tidak mungkin ibumu akan melarangmu kawin seumur hidup.

2. Nita

a) Kuatir

Sikap kuatir Nita tergambar pada kutipan berikut. "Kontrak?” Suara Nita kedengaran penuh kekuatiran. "Kok kedengarannya serius banget. Kau yakin enggak ada hal-hal lain yang terselubung?" (T Marga, 2014:431). Hal di atas menjelaskan bahwa Nita sangat heran jika Fertiti akan dibayar dua puluh juta dollar selama sembilan bulan ia menyanyi karena honor itu sangat tinggi. Nita masih belum percaya akan hal itu. Ia berharap agar Fertiti mau terus terang kepadanya. Karena seandainya selama Sembilan bulan Fertiti tidak dikasih apa-apa. Kontrak cuma setumpuk kertas. Tidak ada artinya bagi orang-orang yang memang sudah berniat mengakali kita.

\section{Pak Lobin}

a) Prihatin

Sifat prihatin Lobin atas apa yang mereka lakukan kepada Fertiti dapat dilihat pada kutipan berikut. "Fukuda mungkin benar, Vash," ujar Lobin beberapa saat kemudian dengan suara tenang dan pelan. "Rasanya sudah cukup kita membuat Fertiti menderita. Permainan ini kurasa sudah selesai." (T Marga, 2004:529). Rasa prihatin dalam kutipan di atas ditunjukkan oleh Lobin yaitu agar mereka selesaikan apa yang dilakukannya bersama Vasthi dan Fukuda kepada Fertiti. Karena ia merasa bahwa apa yang mereka lakukan sudah cukup membuat Fertiti menderita. Seperti pekerjaan-pekerjaan hina yang mereka berikan pada Fertiti, ia dihina, diancam, dipermainkan perasaannya demi membuat mereka senang dan puas.

e. Tokoh Kompleks

1. dr. Kamal

a) Jahat

Watak atau sifat dr. Kamal dihadirkan berubah-rubah. Perwatakannya yang semula perhatian, penyayang dan rasa ingin tahu berubah menjadi watak yang jahat. Sifat jahat Kamal kepada Fertiti yaitu ia melihat Fertiti kerja sebagai penari di klub. Hal tersebut bisa dilihat pada kutipan berikut. " $\mathrm{Ck}$, ck, ck, enggak disangka cantik-cantik kok serendah itu martabatmu! Bisa sampai jatuh begini! Aku tahu kau sekarang sudah miskin. Rupanya gajimu kurang ya. Tapia pa sampai perlu melakoni kerjaan begini? Malah kelihatannya kau senang dijaili orangorang iseng. Rupanya memang punya 
bakat terpendam. Aku salah tafsir selama ini. Kusangka kau lemah gemulai di luar, murni di dalam (T Marga, 2004:471).

Kutipan di atas menggambarkan sifat Kamal pada saat ia datang menonton acara yang dibawahkan oleh Fertiti. Dan di situlah, Kamal pun menyindir Fertiti bahwa Fertiti sudah jatuh miskin sehingga bisa melakoni pekerjaan seperti penari bayaran. Kamal berpikir bahwa itu mungkin saja ini merupakan bakatnya Fertiti yang tersembunyi selama ini. Serta selama ini Kamal salah menilai Fertiti bahwa ternyata Fertiti adalah wanita yang tidak baik.

\section{Mbok Susi}

a) Penipu

Watak atau sifat Mbok Susi dihadirkan berubah-rubah. Perwatakannya yang semula baik hati berubah menjadi watak yang penipu.S ifat Mbak Susi yang menipu Fertiti dapat dilihat pada kutipan berikut. Mbak Susi tersenyum dalam hati reaksi Fertiti. Cerita karangannya mengenai suami yang invalid, tak pernah gagal menggugah perasaan pendengarnya, sehingga mereka rela menuruti perintahnya supaya dia jangan sampai dipecat dan anak-anaknya bisa makan terus (T Marga, 2004:446).

Kutipan di atas menggambarkan sikap mbak Susi yang demi pekerjaan serta anak-anaknya, ia rela menipu perempuan-perempuan muda yang ingin bekerja mandiri agar mereka dapat menuruti segala perintahnya. Karena apabila mereka melawan dan tidak mau bekerja, maka ia akan dipecat bahkan anak anaknya tidak bisa makan.

\section{Tante Oda}

a) Gelisah

Kegelisahan yang berasal dari kata gelisah memiliki arti tidak tentram hatinya, selalu merasa khawatir, tidak tenang, tidak sabar dan cemas. Kegelisahan biasanya digambarkan dengan seseorang yang merasa tidak tentram hatinya. Watak atau sifat Tante Oda dihadirkan berubah-rubah. Perwatakannya yang semula penyayang berubah menjadi watak yang gelisah seperti pada kutipan di bawah ini. "Ada apa, Ti? Kenapa begini malam ke sini? Mana hujan

lebat lagi. Apa enggak bisa pakai telepon saja kalau ada urusan? Ibumu kenapa? (T Marga,2004:24).

\section{KESIMPULAN}

Berdasarkan hasil analisis penelitian di atas dapat disimpulkan bahwa analisis tokoh yang terdapat pada novel Amulet Dari Nubia karya Marga T digolongkan ke dalam enam jenis tokoh yaitu: tokoh utama, protagonis, antagonis, sederhana, dan komplek. Pertama, Fertiti digolongkan ke dalam tokoh utama, protagonis, dan 
sederhana. Kedua, Merti Osorkon digolongkan ke dalam tokoh antagonis dan komplek. Ketiga, Tante Oda digolongkan ke dalam tokoh sederhana. Keempat, dr. Kamal digolongkan ke dalam tokoh protagonis, sederhana dan komplek. Kelima, Vasthi, digolongkan ke dalam tokoh antagonis. Keenam, Nita digolongkan ke dalam tokoh sederhana dan tokoh komplek. Ketujuh, Pak Lobin digolongkan ke dalam tokoh protagonis, tokoh sederhana dan komplek. Kedelapan, Mbak Susi digolongkan ke dalam tokoh protagonis, dan kompleks. Kesembilan, dokter Saul digolongkan ke dalam tokoh antagonis. Kesepuluh, Aisha digolongkan kedalam tokoh protagonis. Kesebelas. Nalub digolongkan kedalam tokoh antagonis. Keduabelas, Tira digolongkan ke dalam tokoh protagonis. Analisis perwatakan yang terdapat dalam novel Amulet Dari Nubia karya Marga T, yaitu:

1. Watak tokoh Fertiti, yaitu: penurut, penakut, peduli dan berkorban, rasa ingin tahu, mengaggumi orang lain, penyayang, cemas, heran, jujur, tidak mudah putus asa, dan pemalu.

2. Watak tokoh Merti Osorkon, yaitu: jahat, perhatian, dan pendendam.

3. Watak tokoh Tante Oda, yaitu gelisah dan penyayang.

4. Watak tokoh Kamal yaitu; baik hati, perhatian, penyayang, rasa ingin tahu,dan jahat.

5. Watak tokoh Vasthi, yaitu: pergaulan bebas, licik, pendendam, serakah, dan sombong.

6. Watak tokoh Nita yaitu, yaitu; kuatir dan takut.

7. Watak tokoh Pak Lobin, yaitu jahat, prihatin, dan jujur.

8. Watak tokoh Mbak Susi, yaitu penipu dan baik hati

9. Watak tokoh dokter Saul, yaitu; jahat.

10. Watak tokoh Aisha, yaitu penyayang

11. Watak tokoh Nalub, yaitu jahat

12. Watak tokoh Tira, yaitu baik hati. 
Analisis Tokoh dan Penokohan dalam Novel Amulet dari Nubia Karya Marga T (Pendekatan Psikologi Sastra)

\section{DAFTAR PUSTAKA}

Priyatni, Endah Tri. 2012. Membaca Sastra dengan Ancangan Literasi

Kritis. Jakarta: Bumi Aksara.

Tarigan, Henry Guntur. 1984. Prinsip-Prinsip Dasar Sastra. Bandung Angka 